\title{
Dynamic testing of systems - Use of TRNSYS as an approach for parameter identification
}

\author{
P. Almeida, M.J. Carvalho*, R. Amorim, J.F. Mendes, V. Lopes \\ Laboratório Nacional de Energia e Geologia (LNEG), Estrada do Paço do Lumiar 22, 1649-038 Lisboa, Portugal
}

Available online 3 March 2014

Communicated by: Associate Editor Jane H. Davidson

\begin{abstract}
Dynamic testing of solar thermal systems is presently defined by ISO 9459-5:2007. The testing methodology is clearly defined in the standard. Presently, laboratories that use Dynamic System Testing methodology only have available for identification of parameters, a closed source program, which is based on a model described by Spirkl and Muschawek (1992). The present paper describes the work done following a different approach for the identification of parameters - use of TRNSYS to simulate the system and use of GENOPT ${ }^{\circledR}$ for optimization. Results are presented, both for thermosyphon and forced circulation systems, and show, in most cases, good agreement (differences lower then $\pm 5 \%$ ) when compared with the results using ISS, v2.7 (from In Situ Scientific Software). Comparison of system energy yield, calculated using TRNSYS for periods higher than one month, with measured energy yield for these periods, was also done for a thermosyphon system showing very good agreement (differences lower than $\pm 3 \%$ ).
\end{abstract}

(c) 2014 Elsevier Ltd. All rights reserved.

Keywords: Dynamic system test; Parameter identification; TRNSYS; GENOPT ${ }^{\circledR}$

\section{Introduction}

Dynamic testing of solar thermal systems is presently defined by ISO 9459-5:2007. The testing methodology is clearly defined in the standard. This standard is referred in EN 12976-2:2006 as testing methodology for factory made systems working either as solar only or preheat systems or as solar plus supplementary systems. Based on testing according to ISO 9459-5:2007, the identification of parameters characterizing the system is needed. Presently testing laboratories that use Dynamic System Testing methodologies use a program from In Situ Scientific Software (version 2.7) - ISS, v2.7, for identification of parameters. The program ISS, v2.7 is a closed source program. This software program is based on a model described by Spirkl and

\footnotetext{
* Corresponding author. Tel.: +351 210924766; fax: +351 217152641 .

E-mail address: mjoao.carvalho@lneg.pt (M.J. Carvalho).
}

Muschaweck (1992). The solar thermal system is modeled considering a plug-flow model for the storage tank, injection of cold water at the bottom and extraction at the top. The power from the collector is delivered to the storage tank at the bottom. The collectors are described according to the Hottel-Whillier-Bliss equation (Duffie and Bechman, 2006), considering only one parameter for the collector heat losses. The storage tank model considers a parameter for characterization of cold water mixing during draw off, as well as, a parameter for characterization of stratification of the storage tank. Systems with auxiliary heat can also be characterized and a parameter represents the part of storage tank influenced by the auxiliary (Spirkl and Muschaweck, 1992). The optimization process for identification of characteristic parameters of the solar thermal system is based on the Levenberg-Marquardt algorithm (Teukolsky et al., 1994). The parameters of the heat balance equation describing cold water draw off and storage tank 